\title{
Different Rationales of Coalition Formation and Incentives for Strategic Voting
}

\author{
Eric Linhart ${ }^{1 *}$, Johannes Raabe ${ }^{2}$ \\ ${ }^{1}$ Technische Universität Chemnitz, Chemnitz, Germany \\ ${ }^{2}$ Universität Kiel, Kiel, Germany \\ Email: *eric.linhart@phil.tu-chemnitz.de
}

How to cite this paper: Linhart, E. and Raabe, J. (2018) Different Rationales of Coalition Formation and Incentives for Strategic Voting. Applied Mathematics, 9, 836-860.

https://doi.org/10.4236/am.2018.97058

Received: June 25, 2018

Accepted: July 27, 2018

Published: July 30, 2018

Copyright () 2018 by authors and Scientific Research Publishing Inc. This work is licensed under the Creative Commons Attribution International License (CC BY 4.0).

http://creativecommons.org/licenses/by/4.0/

\begin{abstract}
Research on strategic voting has mainly focused on electoral system effects but largely neglected the impact of different rationales of coalition formation. Based on a formal model of rational party choice and a simulation study, we systematically investigate this impact and explore the implications. We show that the logic of the underlying coalition formation procedure clearly affects the degree to which the electorate is exposed to strategic incentives regarding the vote choice. The key implications are that sincere voting is more often in the voter's best interest if parties are policy-seeking and if there is increased uncertainty during the stage of coalition formation. Furthermore, we explore how different types of coalition formation affect strategic incentives across the policy space.
\end{abstract}

\section{Keywords}

Strategic Voting, Coalitions, Decision Theory, Simulation

\section{Introduction}

Elections are one of the most important processes in representative democracies and build the basis for a government's legitimacy [1] [2]. With their votes, electors transfer the people's sovereignty to representatives in parliaments. How elections proceed and in which way voters decide to give their votes to candidates or parties are therefore of critical importance for democracies. For the voters it is especially critical that they are aware of the consequences their votes have and how they influence policy outcomes by voting for one or another alternative. In this vein, multiple authors have outlined the importance of electoral systems that are easy to understand (e.g. [3] [4]). However, there are also factors beyond the electoral system that can render voting in one's best interest a com- 
plicated task. Even in the simplest form of Proportional Representation (PR) systems, voters have to consider not only the political positions and potential strengths of parties, but also which parties are or are not likely to form coalitions with each other and which policies the various coalitions would probably implement [5]. While the potential of voting strategically presents a chance for voters to bring outcomes closer to their own preferences, incentives for strategic voting can pose severe normative problems for at least two reasons. First, the need for strategic calculations can overburden voters so that they might not be able to detect which decision is in their best interest [6]. This problem grows if certain groups of voters are left behind and sophisticated voting factually becomes an elite privilege. Second, strategic voting can lead to inner conflicts for voters. If there are incentives to vote strategically, voters can either vote in an expressive way for their preferred party or maximize their expected utility over policy outputs-but not both at the same time like in situations without strategic incentives.

It is thus important to map out under which conditions strategic incentives appear more or less frequently. Tackling the puzzle of strategic voting under PR rules, the existing literature has focused on voters' calculations based on policy positions, party strengths, and the resulting policy expectations (e.g. [7] [8]) in order to explain how often and for whom strategic incentives arise. In this way, the prevalence of strategic voting in PR systems can be explained to a considerable degree. However, existing research typically ignores varying styles of coalition formation. This is problematic because incentives to vote strategically are expected to depend on the way in which parties take sizes and policy positions into account when negotiating over what will be the eventual government coalition which will then decide on policies. Depending on the-office and policy-considerations which determine coalition formation by the parliamentary parties, voters should be faced with varying incentives to vote strategically. Hence, the way a government coalition is typically formed should affect the prevalence of strategic incentives for the electorate at large-a critical characteristic of an election, both from a practical and from a normative perspective. Therefore, the question we seek to investigate in this paper is how different rationales of coalition formation affect the prevalence of incentives for strategic voting.

We contribute to an answer by first outlining how existing research has largely omitted the potential variance with respect to how coalition governments form and how different rationales of government coalitions affect voters' strategic calculations. Second, we present a model to identify rational choices for complex voting decisions including the anticipation of coalition building processes and the legislative stage. We then apply this model and use simulations in order to explore in how far different rationales of coalition formation in combination with characteristics of the party system affect the prevalence of strategic incentives. We conclude by mapping out the key implications of our investigation. 


\section{Models of Strategic Voting in PR Systems}

While the elder literature on strategic voting has been focused almost exclusively on plurality systems, newer contributions have started to overturn "the view that voters don't vote strategically in PR elections" [8] (p. 955). Some analyses which try to measure the share of strategic voters even estimate that strategic voting occurs to a similar degree under pure PR electoral systems and under plurality systems [9] [10]. Whereas, in plurality systems, incentives to vote strategically derive primarily from the attempt not to waste the ballot by voting for a chanceless candidate [11], in PR systems, it is especially the coalition formation process that provides potential for strategic votes [12] (pp. 90-91).

In explaining this initially puzzling phenomenon of strategic voting in PR systems, scholars have developed multi-stage models of strategic voting under PR rules (for an overview, see [8]). Already Downs argued that rational voters in PR systems must consider the following steps of government formation and legislative decision-making in order to maximize the expected utility over their voting decision [5]. Figure 1 visualizes how voters must anticipate what happens after the elections in order to optimally influence policy outputs with their votes. Accordingly, Figure 1 shows that multiple factors potentially complicate voting decisions.

Yet, aforementioned calculations are made fairly complex by the fact that PR electoral systems usually do not see a single party gaining a majority of the parliamentary seats and, hence, coalition formation becomes necessary. Voters base their choices not only on party but on coalition preferences [13]. Furthermore, multiple researchers have highlighted how voters-since they base their choices on expected government policy-try to engage in policy-balancing and vote strategically in order to steer the expected coalition policy in their direction [7] [14]. Critically, voters' expectations regarding the likelihood of different potential coalitions play a vital role for their decision, and these expectations are based on past behavior of the parties as well as coalition signals [15] [16] [17].

What follows is that not only electoral systems but the whole electoral process including all its consequences can render the identification of the optimal vote a complicated challenge. In a laboratory experiment, [6] have shown that the

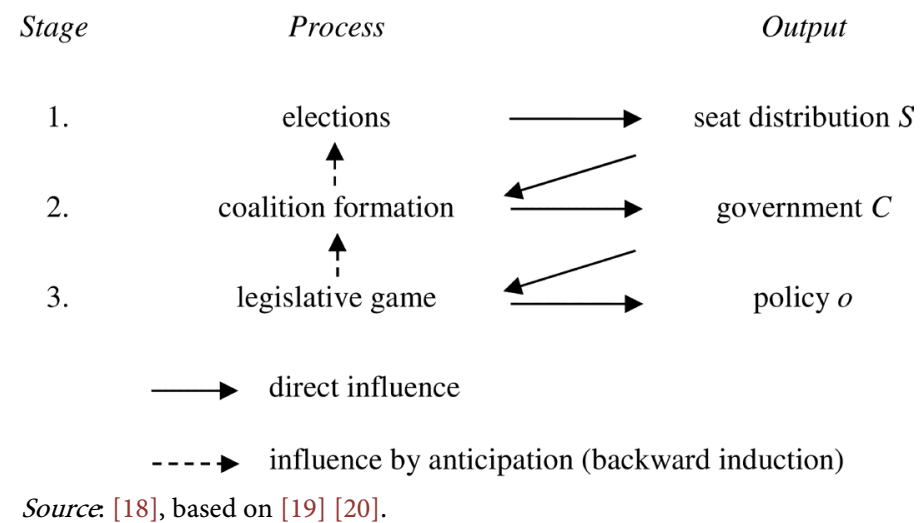

Figure 1. A three stage model of politics. 
question of which kinds of pre-electoral coalitions form heavily influences the share of voters being able to identify what would be their rational choice. Illustrating the importance of taking the stage of coalition formation into account when explaining the prevalence of strategic incentives, [8] (p. 965) has emphasized how the rationale of coalition formation should lead to rather different strategic incentives, concerning both their prevalence as well who is mostly affected by them.

Yet, while existing studies have stretched the importance of voters' expectations regarding specific coalitions [17], they have neglected the impact of variance with respect to the overall rationale that guides parties as they form a coalition government, the general style of government formation in a political system. Existing research largely focuses on stages one and three as depicted in Figure 1 while the coalition formation stage is taken into account only in so far as one specific logic of coalition formation is assumed in order to determine the eventual government coalition-or is consciously left unspecified like in Linhart's model [21] [22].

So far it is almost uniformly assumed that parties care strongly about policy when considering coalition options [7] [23] [24] [25]. However, the role of parties that also may follow rather office-oriented or mixed-motivated rationales of coalition formation is understudied. In the following sections, we will thus explore the impact of different rationales of coalition formation on the prevalence and distribution of strategic incentives among the electorate.

\section{The Model}

For our purpose, we choose to follow Linhart's decision theoretic model ${ }^{1}$ [21] [22] which is more flexible in varying the stage of coalition formation than are later models by [8] or [17] — which have other strengths. This model is an expansion of Riker and Ordeshook's approach for plurality systems [26]. It is assumed that rational voters build preferences over policy outputs $o$, not (only) over parties $P$. This means that for the calculus it does not matter how much a voter likes or dislikes a certain party, but what the election of this party means for the eventual policy output. Formally speaking, $u(P)$ is not a meaningful expression in this model, but $u(o)$ is (cf. also [27]).

Let $n$ be the number of electable parties, then a voter has $n$ alternatives, namely giving her vote to one of the parties $k\left(A_{k}\right)$ (see Table 1$)^{2}$ Riker and Ordeshook do not model this situation in a game theoretic way where all voters would have to react to each other but as a decision under risk [26]. This means

${ }^{1}$ We consciously use a decision-theoretic model in line with a good part of the traditional literature (e.g. [38]). While Indriðason has excellently demonstrated that the problem of a plethora of Nash equilibria in game-theoretic approaches can be solved [8], we are still convinced that—"focusing on the behaviour of an individual voter who cannot coordinate with others in a mass election whose outcome is uncertain" [17] (p. 444) - it is more realistic to assume that voters decide for their own, perceiving their environment as a state of the world.

${ }^{2}$ In the original model, the possibility of abstention is a further alternative, and voting costs are assumed for all alternatives but abstention. As this is not the focus of our analysis we present the reduced model here. It is, however, possible to extend the model so as to include the possibility of abstaining as well as voting costs (see [21] [22]). 
Table 1. The Riker-Ordeshook model as a decision theoretic approach.

\begin{tabular}{ccccc}
\hline & sotw & sotw & $\ldots$ & $E u\left(A_{k}\right)$ \\
\hline$A_{1}\left(\right.$ election of $\left.P_{1}\right)$ & $u\left(S_{11}\right)$ & $u\left(S_{12}\right)$ & $\ldots$ & $E u\left(A_{1}\right)=\sum_{\text {soow } \in \text { ESOTW }} p_{j} u\left(S_{1 j}\right)$ \\
$A_{2}\left(\right.$ election of $\left.P_{2}\right)$ & $u\left(S_{21}\right)$ & $u\left(S_{22}\right)$ & $\ldots$ & $E u\left(A_{2}\right)=\sum_{\text {sotw }_{j} \in \text { SOTW }} p_{j} u\left(S_{2 j}\right)$ \\
$\vdots$ & $\vdots$ & $\vdots$ & & $\vdots$ \\
$A_{n}\left(\right.$ election of $\left.P_{n}\right)$ & $u\left(S_{n 1}\right)$ & $u\left(S_{n 2}\right)$ & $\ldots$ & $E u\left(A_{n}\right)=\sum_{\text {sotw }_{j} \in \text { SOTW }} p_{j} u\left(S_{n j}\right)$ \\
\hline
\end{tabular}

that the collective choice of all voters but ego is considered as a state of the world sotw. We call the set of all states of the world SOTW. Each sotw can be interpreted as (and formally looks like) a preliminary election result in which only the vote of ego is missing. The combination of a state of the world sotw and one of the alternatives $A$ then leads to a final electoral result and a corresponding seat distribution $S$. The expected utility $E u$ of an alternative $A$ then equals the sum of all utility values resulting from $A$ weighted by the probability $p$ of the respective states of the world. The rational choice is the alternative with the highest expected utility.

In the standard model for plurality systems only two parties have a realistic chance to form the government. ${ }^{3}$ This makes stages 2 and 3 in Figure 1 trivial: The majority party can form a government (stage 2 ) and implement her preferred policy (stage 3). Consequently, utilities over seat distributions $S$ and over policy outputs $o$ converge, and only two policy outputs are possible: $u(S) \equiv u(o)=u\left(y_{1}\right)$ or $u\left(y_{2}\right)$, where $y_{k}$ denotes the ideal position of a party $P_{k}$ and $P_{1}$ and $P_{2}$ are the largest parties.

In situations with more than two parties, typically emerging under PR or mixed electoral systems, the model is much more complicated. In general, there is no party with an absolute majority, i.e. two or more parties must form a coalition $C$. The coalition government has to compromise on a policy $y_{C}$ which is unlikely to be any party's ideal position. Hence, stages 2 and 3 of the political process become non-trivial.

The extension for any electoral system and party systems of any structure by Linhart works as follows [21] [22]. Since the rational voter's utility refers to policy outputs $o$, the three-stage model must be solved from the end via backward induction. Starting there, preferences over policy outputs are measured by distances in a policy space $O$ [5] in which oftentimes squared distances are used [28] [29]:

$$
u_{i}(o)=-\left(y_{i}-o\right)^{2} \text { for all } o \in O \text {. }
$$

If $\pi_{C}(o)$ is a probability function which describes the likelihood that a government $C$ implements a policy $o$, then the expected utility of voters over coalition governments can be estimated as

$$
E u_{i}(C)=\sum_{o \in O} \pi_{C}(o) \cdot u_{i}(o)=-\sum_{o \in O} \pi_{C}(o) \cdot\left(y_{i}-o\right)^{2}
$$

${ }^{3}$ We ignore the possibility of a tie here, which is relevant in the original model but not for our analysis. 
for finite policy spaces $O$, or

$$
E u_{i}(C)=\int_{o \in O} \pi_{C}(o) \cdot u_{i}(o) d o=-\int_{o \in O} \pi_{C}(o) \cdot\left(y_{i}-o\right)^{2} d o
$$

for infinite policy spaces $O$, respectively.

A reasonable simplification of formulas (2) and (2') can be found, for example, in Bandyopadhyay and Oak's work [30] (see also [31]) where a coalition's policy is estimated as the mean policy of its members, weighted by the parties' sizes, i.e.

$$
y_{C}=\sum_{P_{k} \in C} y_{k} \cdot s_{k} / s_{C}
$$

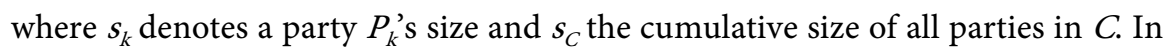
terms of formula (2) and (2') this means that $\pi_{C}\left(y_{C}\right)=1$, while $\pi_{C}(o)=0$ for all $o \neq y_{C}$. As a consequence,

$$
u_{i}(C)=-\left(y_{i}-y_{C}\right)^{2} .
$$

We follow formulas (3) and (4) because of their simplicity and straightforwardness (cf. [24]). This way is the easiest possibility to estimate policy outputs depending on the coalition $C$ and the sizes of $C$ s members.

Going back one stage and denoting by $q_{S}(C)$ the probability that, given a seat distribution $S$, a government $C$ forms, it is possible to construct expected utility functions for voters over seat distributions:

$$
E u_{i}(S)=\sum_{C} q_{S}(C) \cdot u_{i}(C)=-\sum_{C} q_{S}(C) \cdot\left(y_{i}-y_{C}\right)^{2}
$$

With help of formula (5), the entries of all cells in Table 1 can be computed, and the Riker-Ordeshook model can be applied also to multi-party systems. Equation (5) highlights that the question of how likely a coalition will form, $q_{S}(C)$, strongly influences the rational calculus. As it is our research question which coalition building procedures raise or confine incentives for strategic voting, we abstain from fixing $q_{s}(C)$ here but compare effects of different alternatives (i.e. different rationales of coalition formation) in our simulation.

In order to completely solve the utility maximization problem, we have to specify the $p(s o t w)$ values needed for the computation of the alternatives' expected utilities. According to the decision theoretic standard approach we would have to fix a number of voters, combine all possible voters' decisions (except ego's decision) to states of the worlds and choose a meaningful probability function $p$. This standard procedure is problematic for two reasons. First, any chosen probability function would be ad hoc, and second, for a reasonable number of voters, there are more states of the world to consider than standard computers can deal with. For this reason, we do not compute expected utility values according to the standard approach but use an approximation. Technical details are described in Appendix I.

\section{Simulation}

In order to explore the consequences of different general rationales of coalition formation and derive empirical implications, we simulate party systems and detect strategic incentives using the model introduced above. In this way we are 
able to generate the variation of cases needed in order to fully map out the consequences of varying styles of coalition formation (for similar approaches see [32] [33] [34] [35]).

Our simulation is designed as follows. We let the number of parties run between 3 and 7 and simulate 2000 party systems for each number of parties. ${ }^{4}$ Since we research the effect of coalition formation procedures, one- and two-party-systems are not of interest. Further, an inspection of our simulated data shows that seven-party-systems are highly fragmented (see Appendix II), so that simulations with eight or more parties are not assumed to deliver additional insights. We allocate party positions $y_{k}$ and party sizes $s_{k}$ to every party by random choice with help of the random function in Mathematica@. The party positions are drawn from a uniform distribution over the $[0,1]$ interval. Party sizes are simulated as follows. Each party is randomly assigned a number of seats between 1 and 101-the latter is the size of our simulated parliaments and therefore the maximum possible number of seats for a party. The party sizes then are normalized by division through the total of all party seats so that the parliament sizes equal 101 seats. Before a simulated party system becomes part of our data set, we test it for two conditions: First, every party must hold at least one seat after normalization, so that the party system is a real $n$-party-system, not actually an $(n-1)$-party-system. Second, no party may hold an absolute majority of the seats since, then, government formation becomes trivial. If one of these conditions does not hold, we delete the case and re-draw. While alternative mechanisms make sense, too, but might lead to different party systems, it is noteworthy that we finally verified that our simulated party systems resemble factually existing party systems. The respective summary statistics can be found in Appendix II.

We base our exploration on established theories of coalition formation in order to cover a broad range of possible rationales. For each party system, we apply nine different coalition building procedures following standard coalition theories (see below for details) which vary in their assumptions about how much parties care about gaining offices and influencing policy respectively. ${ }^{5}$ We order these procedures beginning with coalition formation procedures with strict emphasis on offices, neglecting any role of policy. Step by step, policy becomes more and offices become less relevant, ending with scenarios in which coalition formation is solely depending on policy aspects. This thread allows us to systematically show how and which office considerations influence incentives for strategic voting compared to policy considerations.

Following theories which assume office seeking parties, our first bloc of procedures considers minimal winning coalitions only [36]. The strictest form of office-orientation is the deterministic formation of the smallest size coalition ${ }^{4}$ Two repetitions of this simulation confirmed the robustness of the results so that 2000 cases are sufficient.

${ }^{5}$ Gschwend and Hooghe as well as Meffert and Gschwend research strategic voting behavior in experimental settings but focus more strongly on the role of specific coalition signals instead of the impact of different general logics of coalition formation [24] [50]. 
(based on parliamentary seats), independent of all further factors [37] [38]. We model this procedure in

C1: $q_{S}(C)=1$ if $C$ is smallest size; $q_{S}(C)=0$ otherwise. If two or more coalitions are smallest size, one of them is selected randomly.

In order to add an element of uncertainty (beyond tie-breaking rules) to the process of coalition formation, we soften strictly deterministic rules: $\mathrm{C} 1$ is thus contrasted with a similar procedure in which coalition bargaining is more flexible, i.e. no coalition comes into office with a probability of 1 :

C2: $q_{S}(C)=0.5$ if $C$ is smallest size or second-smallest size; $q_{S}(C)=0$ otherwise.

This variation implies more leeway given to parties actually bargaining over various coalitions, which is i) more realistic, ii) makes more parties potentially relevant to influence policy outputs, and iii) softens the strict assumption that office seeking parties will necessarily form the smallest size coalition.

Alternatively, Leiserson proposes to minimize the number of coalition parties instead of the parties' cumulative seat share-a coalition formation logic which he labels the "bargaining proposition" [39]. We follow this idea in scenarios 3 and 4 :

C3: $q_{S}(C)=1$ if $C$ minimizes the number of parties; $q_{S}(C)=0$ otherwise. If two or more coalitions minimize the number of parties, one of them is selected randomly.

Likewise $\mathrm{C} 2, \mathrm{C} 4$ softens the rule's determinism:

C4: $q_{S}(C)=1 / \# C^{*}$ if $C$ minimizes the number of parties; $q_{S}(C)=0$ otherwise. $\# C^{*}$ denotes the number of coalitions which minimize the number of parties.

In order to consider findings of policy oriented coalition theories, we follow Leiserson's approach of minimal range coalitions [40] (see also [41]) and combine it with the bargaining proposition in scenario 5 :

C5: $q_{S}(C)=1$ if $C$ minimizes the number of parties; $q_{S}(C)=0$ otherwise. If two or more coalitions minimize the number of parties, the one with the smallest range is selected. If still two or more coalitions remain, one of them is selected randomly.

Formally, it looks as if the policy aspect mattered very rarely only in special cases of parity regarding the bargaining proposition. This would be true if the office rule were "smallest size", where the seat minimizing coalition usually is unique. In most of the cases, however, there are two or more coalitions with a minimal number of parties, so that the policy aspect comes into operation.

Making one more step towards policy orientation, we turn away from the strictest forms of office seeking theories and formulate as a baseline condition only that coalitions should be minimal winning and choose the minimal range coalition out of this set. Although this scenario still includes office aspects, the focus clearly lies on policy. This formation procedure functions analogous to De Swaan's policy seeking modeling approach in which he, too, considered minimal winning coalitions only [41]. Formally, we model this scenario as: 
C6: $q_{S}(C)=1$ if $C$ is minimal winning and minimizes the range; $q_{S}(C)=0$ otherwise. If two or more minimal winning coalitions minimize the range, one of them is selected randomly.

The respective less deterministic scenario is

C7: $q_{S}(C)=0.5$ if $C$ is minimal winning and has the smallest or second-smallest range; $q_{S}(C)=0$ otherwise.

Giving up office considerations completely, we conclude with scenarios 8 and 9 which reflect the idea that party competition consists of two competing blocs of parties along the left-right spectrum [42]. From Black's Median-voter theory we know that the median position beats any other proposal in a pairwise vote, i.e. the median position is a Condorcet winner [43]. The median player-if she exists-gets support for her ideal position from players to her right against proposals to her left and vice versa. This means that she has the choice to form a coalition with either the players to her right or to her left. In coalition theory, we often find other denominations like "pivotal player" [41] or "central player" [44] [45] which are very close or identical to this concept. Denoting the party farthermost left by $p_{L}$, the party farthermost right by $p_{R}$, and the median party by $p_{M}$, scenario 8 is formally defined as

C8: $q_{S}(C)=1$ for $C=\left\{p_{L}, \cdots, p_{M}\right\} ; q_{S}(C)=0$ otherwise.

The choice of the coalition left of the median follows a without-loss-of-generality assumption. This means that results would not change if we replaced the coalition by that right of the median $\left(C=\left\{p_{M}, \cdots, p_{R}\right\}\right)$. Scenario 9 , finally, is the non-deterministic pendant to scenario 8 . Here, both the left and the right coalition occur with a probability of 0.5 .

C9: $q_{S}(C)=0.5$ for $C=\left\{p_{L}, \cdots, p_{M}\right\}$ and for $C=\left\{p_{M}, \cdots, p_{R}\right\} ; q_{S}(C)=0$ otherwise.

Table 2 summarizes the coalition formation scenarios and shows attributes of

Table 2. Attributes of the applied coalition formation procedures.

\begin{tabular}{|c|c|c|c|c|c|}
\hline Scenario & Rule & minimal winning & distance relevant & connected & deterministic \\
\hline $\mathrm{C} 1$ & smallest size I & $\mathrm{x}$ & & & $\mathrm{x}$ \\
\hline $\mathrm{C} 2$ & smallest size II & $\mathrm{x}$ & & & \\
\hline $\mathrm{C} 3$ & bargaining proposition I & $\mathrm{x}$ & & & $\mathrm{x}$ \\
\hline $\mathrm{C} 4$ & bargaining proposition II & $\mathrm{x}$ & & & \\
\hline C5 & $\begin{array}{l}\text { bargaining proposition } \\
\text { and minimal range }\end{array}$ & $\mathrm{x}$ & $\mathrm{x}$ & & \\
\hline C6 & minimal range I & $\mathrm{x}$ & $\mathrm{x}$ & & $\mathrm{x}$ \\
\hline $\mathrm{C} 7$ & minimal range II & $\mathrm{x}$ & $\mathrm{x}$ & & \\
\hline $\mathrm{C} 8$ & central player I & & $\mathrm{x}$ & $\mathrm{x}$ & $\mathrm{x}$ \\
\hline $\mathrm{C} 9$ & central player II & & $\mathrm{x}$ & $\mathrm{x}$ & \\
\hline
\end{tabular}

Notes: the column-heading "minimal winning" implies that a scenario will certainly lead to a minimal winning coalition where this criterion applies, but not that a minimal winning coalition cannot occur where this criterion does not apply; the same holds for the column-heading "connected". 
the different procedures. Most importantly, we see that from 1 to 9, office consideration become less, and policy aspects more important. For scenarios 1 to 7 , any coalition government is minimal winning, while this is not guaranteed in scenarios 8 and 9. This does not mean that minimal winning coalitions cannot be formed in these scenarios, but surplus coalitions are possible, too, since dummy players-which are not necessary for a coalition's majority-may be located between $p_{L}$ and $p_{M}$ (or between $p_{M}$ and $p_{R}$ ). On the other hand, the connectedness of coalitions (cf. [46]) is guaranteed in the last two scenarios only. If surplus coalitions are assumed not to form (like in scenarios 1 to 7 ), the resulting exclusion of dummy players might distort a coalition's connectedness. This does not mean that policy distances do not matter at all. On the contrary, besides scenarios 8 and 9 , aspects of policy distance play a role in three further scenarios (5 to 7).

The right column points to an aspect beyond office and policy. It indicates whether or not coalition formation is completely deterministic or, formally, whether there is one certain coalition with $q_{S}(C)=1$. Table 2 shows that every strict deterministic scenario has a respective counterpart. An exception is scenario 5 , in which the probabilistic component of scenario 4 is replaced by the integration of policy aspects.

Having specified the coalition building rules, the formal model as described above is complete. The rational calculus of voting can be computed for each of the 90,000 simulated cases (2000 drawings for 5 different numbers of parties times 9 coalition building scenarios). As concerns the output variable, we primarily seek to investigate how different rationales of coalition formation affect the incentives for strategic voting for the whole policy space. In order to derive an aggregate measure reflecting the overall characteristics of an electoral situation, we go through all policy positions between 0 and 1 in steps of 0.01 . For each position, we both identify the closest party to this position (sincere choice) ${ }^{6}$ and calculate the party that emerges as the result of a rational calculus (rational choice). The share of positions for which the rational choice does not coincide with a vote for the closest party (i.e. a sincere choice) is the dependent variable in our analyses-we deem this the strategic share of an electoral situation. The higher this share, the more incentives for strategic voting can be found in the scenario, and the more this scenario is concerned with the normative problems of strategic voting as outlined in the introduction.

\section{Simulation Results and Implications}

The structure of our results section is as follows. First, we derive implications with respect to the different coalition formation procedures. Second, we focus on effects of party system characteristics and present comparative statics including all variables. Finally, we explore at which positions incentives to vote strategical-

\footnotetext{
${ }^{6}$ Working within a Downsian framework, preferences emerge endogenously from our simulation-based on distances between voters and parties-and are thus assumed to be unaffected by factors outside the policy space. Therefore, the sincere choice always coincides with the party that is closest to a voter.
} 
ly occur more or less frequently and thus focus on the distribution of strategic incentives under different circumstances.

\subsection{Effects of Different Logics of Coalition Formation}

Figure 2 shows mean values and standard deviations of our dependent variable strategic share for the various coalition formation rules under research. The graph in the left represents the average of all cases. Generally, we find high values for the strategic shares. The mean of all cases equals $60.2 \%$ (implying that for $60.2 \%$ of the positions in the policy space the sincere choice is not the rational choice), the lowest mean value can be found in scenario C4 (47.7\%), the highest in scenario C3 (71.3\%). The mean standard deviation is 0.224 (ranging from 0.173 in $\mathrm{C} 8$ to 0.259 in C2). This overview shows that there is variation within but also between the nine assumed procedures.

The relatively high values for strategic share are partially driven by the kind of modeling since our calculus of voting includes all types of strategic voting (making some coalitions more and others less likely by strengthening/weakening certain parties, intra coalition balancing of policy outputs, considering wasted votes with regard to policy outputs etc.) and is not restrained to special types. Secondly, the calculus is rigorously focused on policy outputs which are influenced by government parties only. ${ }^{7}$

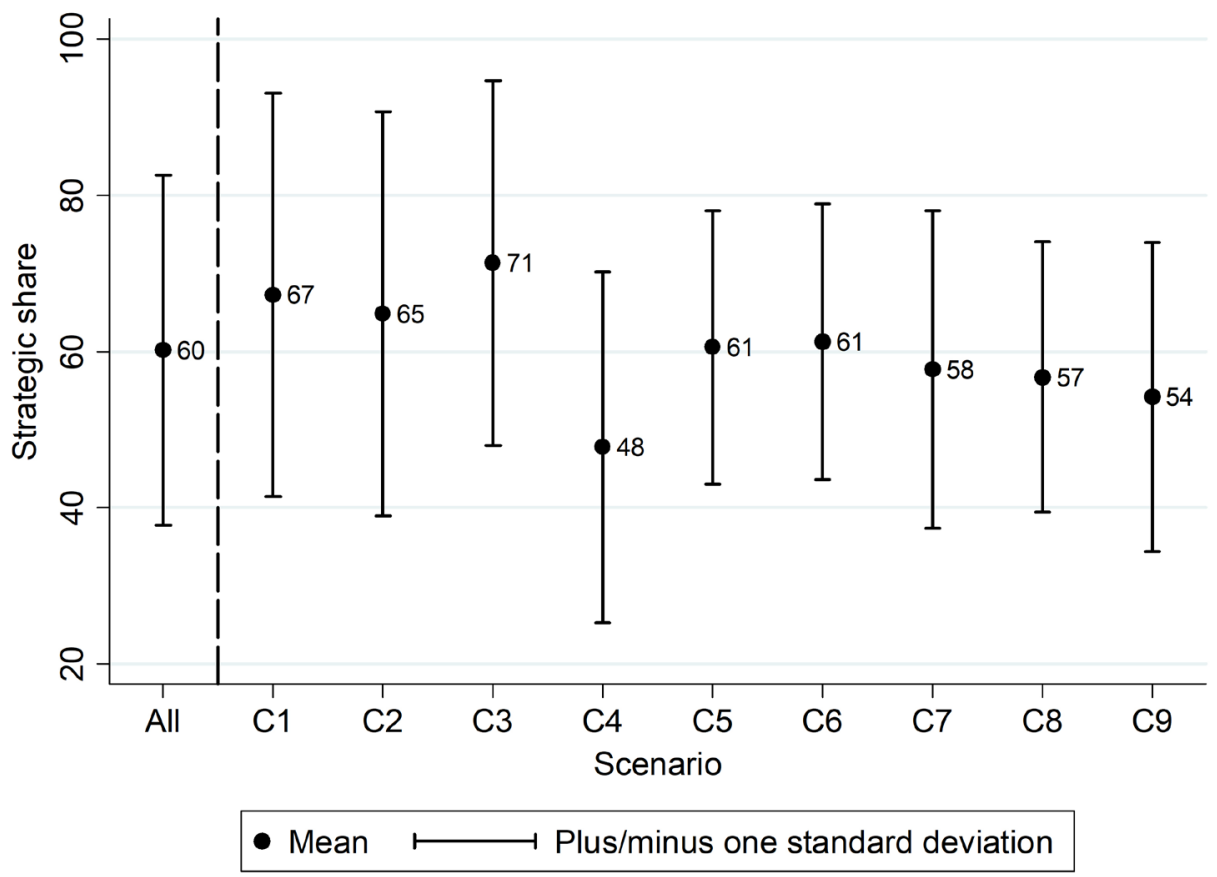

Figure 2. Strategic shares (in percent) for the different coalition building procedures.

${ }^{7}$ While we generally defend this assumption as it is in accordance with the three-stage model of politics (see Figure 1) as well as the Riker-Ordeshook calculus (and because a more elaborate way of estimating legislative outputs would contradict formal models' demand of simplicity), we concede that this approach might ultimately overestimate strategic incentives. On the other hand, we do not expect any systematic bias with regard to our results since this rigorousness is due to the general model, not to certain coalition building scenarios. 
A first inspection of Figure 2 yields important implications. Regarding the impact of the motives that drive parties, we find higher mean strategic shares in the left where rules with a higher office orientation can be found, and lower values in the right where policy considerations play a larger role, suggesting that the more important policy considerations become for parties bargaining over coalition government the less prevalent are strategic incentives among the electorate. This is due to the fact that purely office seeking parties ignore policy disagreements between parties. Compared to (at least partially) policy seeking parties, they are more likely to form coalitions together with parties that are far away in the policy space. Consequently, policy compromises are likely to be farther away from the parties' ideal points in such coalitions. From a voter's view this implies that a party which is close to him might nevertheless finally implement policies far away from the voter's position. This risk is smaller if parties care about policy during the coalition formation process and consider policy distances when choosing their coalition partners.

Furthermore, Figure 2 suggests that especially the scenarios where the connectedness of coalitions is guaranteed (C8, C9) have a diminishing effect on the prevalence of strategic incentives. If coalitions are not necessarily connected, a voter might find herself in a position where electing the party closest to her is not a rational choice-not because its inclusion into the government would have undesirable policy effects but because it might not be considered for the governing coalition as, despite the ideological fit, it is inconsequential, for example, for the minimal winning status of the governing coalition. This means that, in unconnected coalitions, voters must strategically think of which parties close to them are or are not likely to be part of the government. In connected coalitions, this is the case much less frequently.

Turning to the impact of uncertainty, strategic incentives are less prevalent in less deterministic scenarios $(\mathrm{C} 2, \mathrm{C} 4, \mathrm{C} 7, \mathrm{C} 9)$ than in their deterministic equivalents $(\mathrm{C} 1, \mathrm{C} 3, \mathrm{C} 6, \mathrm{C} 8)$. This effect results from the openness of the coalition formation process. The more open a government formation process is, the more parties are likely to influence governmental policy, and the fewer are therefore excluded as non-rational alternatives.

Table 3 underscores the interpretation of Figure 2. Contrasting groups of scenarios with specific attributes with the converse groups without these attributes, we are able to assess first differences. Both policy variables reduce the mean strategic share value. When distance is relevant, it is lower by 4.7 percentage points. ${ }^{8}$ If a rule guarantees the connectedness of governing coalitions, the share shrinks by 6.0 points. We find an even larger effect when comparing deterministic and non-deterministic rules. The latter's strategic share is 7.3 percentage points smaller. In sum, policy oriented government formation appears to alleviate the problem of a strong prevalence of strategic incentives in an

${ }^{8}$ Since our simulated data produces a very large $N$ of 90,000 it is neither surprising nor worth discussing that all differences are statistically significant. We therefore only refer to the mean differences. 
Table 3. Assessing the impact of different scenarios.

\begin{tabular}{cccc}
\hline & Yes & No & Difference (Yes - No) \\
\hline Distance relevant & $0.581(0.187)$ & $0.628(0.260)$ & -0.047 \\
Connected & $0.555(0.186)$ & $0.615(0.232)$ & -0.060 \\
Deterministic & $0.634(0.213)$ & $0.561(0.231)$ & 0.073 \\
Smallest size (C1, C2) & $0.660(0.259)$ & $0.585(0.210)$ & 0.075 \\
Bargaining proposition (C3, C4, C5) & $0.598(0.234)$ & $0.603(0.220)$ & -0.005 \\
Minimal range (C5, C6, C7) & $0.598(0.186)$ & $0.603(0.241)$ & -0.005 \\
Central player (C8, C9) & $0.555(0.186)$ & $0.615(0.232)$ & -0.060 \\
\hline
\end{tabular}

electoral situation. Furthermore, increased openness of formation procedures sees sincere and rational choices coincide more often.

Breaking down the various office and policy oriented models, we again see the structure discussed above. The most rigorous office oriented formation rule (smallest size) leads to the highest differences in means (7.5 percentage points), the strictest policy oriented rule (central player) to the lowest $(-6.0$ percentage points). The others lie in-between with -0.5 percentage points. Yet, there are two results that do not seem to fit the general patterns outlined so far.

First, it is striking that the office oriented rule bargaining proposition exerts a, albeit small, negative effect. The slightly negative difference in means, however, does not contradict our findings with respect to the effect of different rationales of coalition formation. Since the reference category includes policy oriented rules but also the stricter office oriented smallest size rule, it simply seems to be the case that the effects of $\mathrm{C} 1$ and $\mathrm{C} 2$ are stronger than those of $\mathrm{C} 6$ to C9. Further, the bargaining proposition sample also includes one rule (C5) which at least partially considers policy.

Second, we might expect a strong monotonic decline of the differences in means as we move from office to policy oriented coalition building procedures, but see the same values for bargaining proposition and minimal range. This is mainly an effect of C4's results whose outlier position can already be seen in Figure 2. The explanation for this initially surprising result is as follows. Assume a coalition formation game in which all coalitions are equally probable. In such a situation where anything is possible, strategic incentives are very rare and voting for the closest party is oftentimes the rational strategy. For a small number of parties like three or four, $\mathrm{C} 4$ is very likely to produce exactly this situation: (nearly) all minimal winning coalitions consist of two parties; C4's $q_{s}(C)$ function thus makes (nearly) all minimal winning coalitions equally probable (see also footnote 9). Thus, what seems puzzling based on the general implication that office oriented government formation will drive up the strategic share is easily explained by taking the role of increased uncertainty into account. The results regarding the effect of uncertainty based on the simulated data also fit very well with recent findings that increased uncertainty about outputs should 
lead to more sincere voting (e.g. [7], p. 322; also see [47]).

\subsection{Party System and Combined Effects}

Continuing with the party system characteristics of parliamentary fragmentation and ideological polarization, Figure 3 shows the strategic shares for each scenario by the number of parties. We see the same tendency in all scenarios: The more parties are in a system, the higher the mean strategic share. At the same time, we observe variation between the different scenarios. While in scenarios $\mathrm{C} 4$ to $\mathrm{C} 9$ the boxes (encompassing 50 per cent of the cases) are rather small, they are clearly larger especially under C3. In particular, this is the case for three- and four-party-systems. ${ }^{9}$ We further see that the effect of the number of parties itself is larger in some scenarios (e.g., in C1 and C2) and smaller in others (like C5 and C6). Figure 3 also illustrates again the different basic levels of strategic shares in the various scenarios-with values generally decreasing from $\mathrm{C} 1$ to $\mathrm{C} 9$. We chose to use the pure number of parties as an indicator of party system fragmentation as it makes the interpretation of the results more straightforward. Applying the more sophisticated effective number of parties (see [48]) leads to highly similar results. Overall, the strong correlation between the number of parties and the strategic share is most probably linked to parties' leeway in forming governments. Ceteris paribus, the set of possible coalition governments grows exponentially with the number of parties. Parties' leeway is much more limited in cases where only few coalition governments are possible than in cases where a plethora of possible coalitions exist. The more fragmented a party system is, the larger is the parties' leeway and the less certain it is for voters to which policy their votes would lead. As the number of coalition options increases it clearly appears that so do the incentives to vote strategically in order to maximize one's utility.

We assess the effect of party system polarization ${ }^{10}$ within regression analyses concluding our primary empirical investigation (see Table 4). Model 1 which is based on the whole sample confirms the strong positive effect of party system fragmentation and suggests a positive effect also for polarization. However, the uncertainty around this effect is huge in comparison. ${ }^{11}$ The regression analysis furthermore largely reproduces the results from Table 3 regarding differences in the coalition formation rules. The only larger difference is that the effect of connectedness is estimated to be less pronounced (lowering the strategic share by 3.1 percentage points as opposed to 6 points as suggested by the first differences reported above)-which makes sense given that the model controls for policy distance. Overall, for our simulated dataset, differences in coalition formation and party system characteristics explain about 31 percent of the variation in strategic shares.

${ }^{9}$ The panel for C4, with very low strategic share rates in three- and four-party systems, visualizes the above discussion with respect to the effect of increased uncertainty.

${ }^{10} \mathrm{We}$ measure polarization as the standard deviation of the policy positions within each party system [51].

${ }^{11}$ This could also be seen in a scatterplot which we do not show here. 
C1

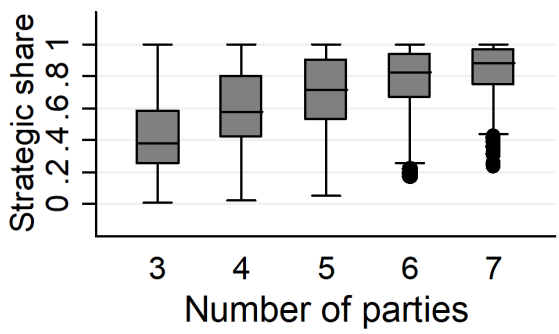

C3

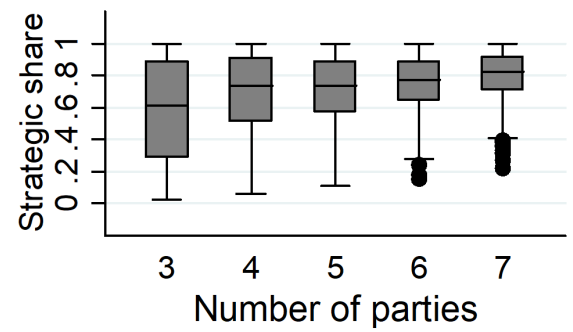

C5

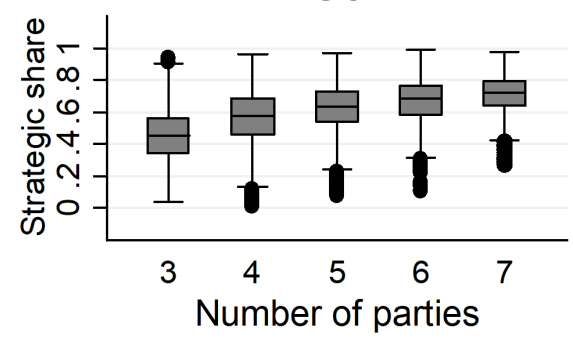

C7

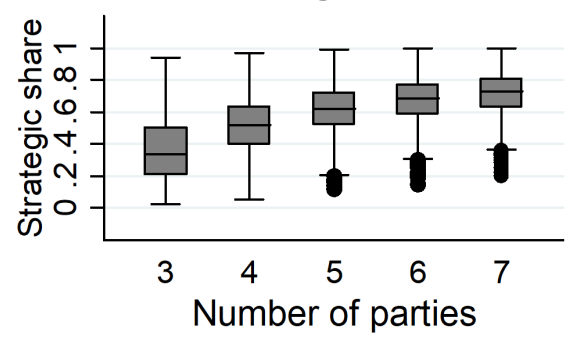

C9

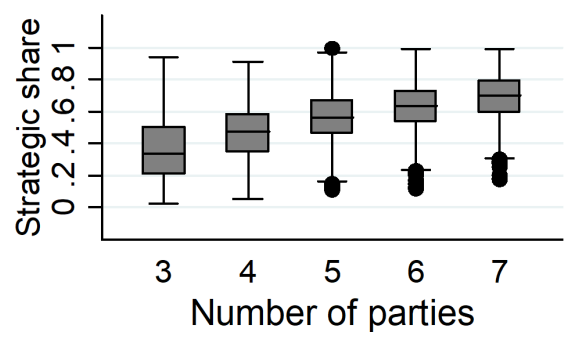

C2

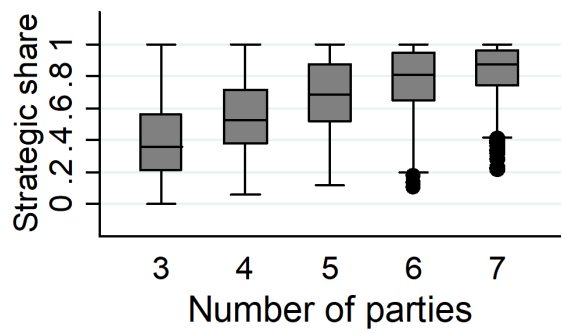

C4

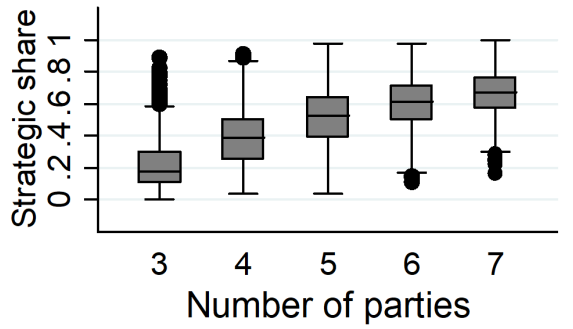

C6

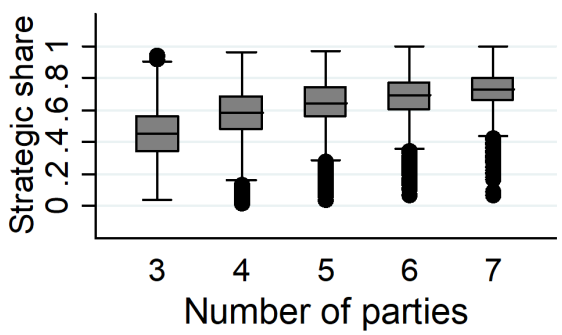

C8

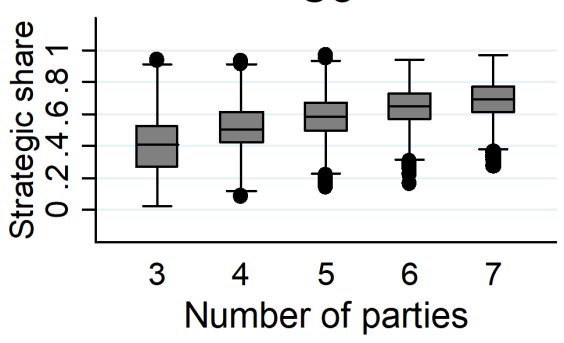

Figure 3. The effect of party system fragmentation. 
Table 4. Regression models.

\begin{tabular}{ccc}
\hline & Model 1 & Model 2 \\
\hline Number of parties & $0.081^{* * *}$ & $0.081^{* * *}$ \\
& $(0.0004)$ & $(0.0042)$ \\
Polarization & $0.052^{* * *}$ & 0.049 \\
& $(0.0073)$ & $(0.0693)$ \\
Distance relevant & $-0.042^{* * *}$ & $-0.042^{* * *}$ \\
& $(0.0014)$ & $(0.0137)$ \\
Connected & $-0.031^{* * *}$ & $-0.032^{*}$ \\
& $(0.0017)$ & $(0.0164)$ \\
Deterministic & $0.076^{* * *}$ & $0.076^{* * *}$ \\
& $(0.0013)$ & $(0.0121)$ \\
Constant & $0.171^{* * *}$ & $0.172^{* * *}$ \\
$\mathrm{~N}$ & $(0.0031)$ & $(0.0295)$ \\
$\mathrm{R}^{2}$ & 90,000 & 1000 \\
\hline
\end{tabular}

Notes: ${ }^{*} \mathrm{p}<0.1,{ }^{* *} \mathrm{p}<0.05,{ }^{* * *} \mathrm{p}<0.01$ standard errors in parentheses.

Based on Model 2 we examine whether or not our results would remain statistically significant if we used a more common number of cases. We therefore iteratively draw a random sample of 1000 from our dataset 1000 times and run the statistical model for each random sample (see [49] for a larger methodological discussion). The results shown for Model 2 are based on the average variance-covariance matrix; $\mathrm{R}^{2}$ is the average $\mathrm{R}^{2}$.

The regression analyses yield the same implications as our inspections of Figure 2 and Table 3 . The number of parties and party system polarization both raise the strategic share. The same is true for deterministic coalition formation rules, while rules in which policy distances do play a role and/or in which the connectedness of the governmental coalition is guaranteed lower the strategic share. The largest coefficients can be found for the number of parties and deterministic rules. The strategic share goes up by 8.1 percentage points per additional party and by 7.6 percentage points if deterministic coalition formation rules are applied. A full policy orientation (distance is relevant and the connectedness of coalitions is guaranteed) drives down the strategic share by 7.3 percentage points.

Model 2 clearly exposes that there is a lot of uncertainty around the effect of polarization. For a more realistic number of cases, the effect is far from being statistically significant $(\mathrm{p}=0.477)$. It is also worth mentioning that for Model 2 , the variance around the effect of connectedness is comparably large (leading to $p$ $=0.053)$. Yet, the policy effect is captured quite clearly by the distance variable.

\subsection{The Distribution of Strategic Incentives}

After having assessed strategic incentives via a summary score for every electoral situation, it is important to further explore which positions are affected by stra- 
tegic incentives. In a first step, we ask whether it is voters in the political centre or at political extremes that are most often faced with strategic incentives-and whether this varies by coalition formation procedure. Figure 4 shows the spatial distribution of strategic shares under three different coalition formation procedures. Precisely, the $y$-axis denotes for each position on the policy (x-)axis the share of cases in which voters need to vote strategically in order to act rationally (denoted as the share of strategic votes). Figure 4 immediately suggests that there is no general trend as to which positions are most often affected by strategic incentives and that the logic of coalition formation emerges as a critical moderating variable.

The procedures depicted in Figure 4 represent typical cases, as summary statistics of all procedures in Appendix III show. Office-oriented procedures are represented by $\mathrm{C} 2$ (smallest size II). These procedures can be characterized by a generally high level of strategic incentives for all positions with comparably low variation (between 60 and 67 percent). However, positions in the political centre are more often accompanied by strategic incentives than positions at the extremes. The policy-oriented procedures do not show a homogeneous picture as the results depend on whether or not there is bloc competition. C7 (minimal range II) here represents the policy-seeking procedures without the bloc logic. In contrast to the other cases, it is the more extreme positions that come with strategic incentives more often under the minimal range coalition formation procedure. Furthermore, the differences between extreme and centre positions are quite marked with strategic shares differing by as much as 22 percentage points. Thus, for these policy-seeking scenarios, strategic shares are driven by positions at the outer margins of the party system as opposed to those in the political centre where strategic incentives occur much less often. Finally, C9 (central player

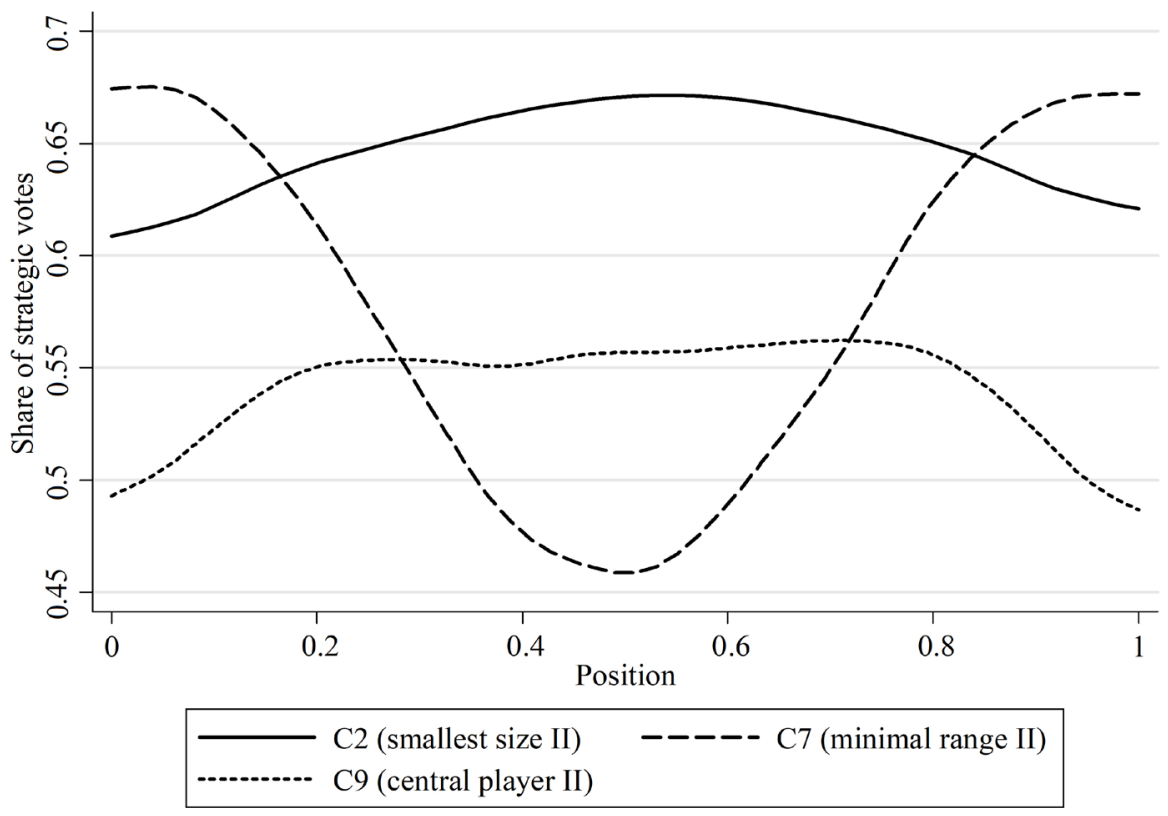

Figure 4. Comparing scenarios across the policy space. 
II)-representing a policy-seeking, bloc-building logic of coalition formation-exhibits trends much more akin the office-seeking procedures discussed above but on a distinctly lower level. When political blocs compete for government, variation in strategic shares is fairly low with no pronounced difference between centre and extreme positions. However, positions at the extreme right or left are slightly less concerned with strategic incentives. These findings with respect to the policy oriented scenarios are also well in line with what Bargsted and Kedar find when assuming that governments, as voters, are driven by policy concerns [7].

As it is not only of interest which (absolute) positions are more or less affected by strategic incentives but also if it is positions close or farther away from the parties' positions, we examine in a next step whether an effect of the distance to the closest party can be observed in a logit model predicting when a particular position will present a strategic incentive (i.e. the rational choice is not the sincere choice). Table 5 shows respective multivariate regressions including-beyond the distance variable-the most relevant variables from our results above and corresponding interaction effects. As for Table 4, we additionally show a second model with random bootstraps to get a more realistic number of cases.

It is first worth mentioning that the analysis confirms our results above. Strategic incentives occur less often in scenarios with policy oriented coalition formation rules but more often if rules are deterministic (while the significance of the latter effect is questionable). More parties lead to more strategic incentives. Interpreting the impact of distance the regression estimates suggest a negative effect under most circumstances, implying that the farther away a voter's position is

Table 5. Logit regressions including distance variables.

\begin{tabular}{ccc}
\hline & Model 1 & Model 2 \\
\hline Number of parties & $0.351^{* * *}$ & $0.351^{* * *}$ \\
Policy scenario (C5-C9) & $(0.001)$ & $(0.05)$ \\
& $-0.345^{* * *}$ & $-0.341^{\star}$ \\
Deterministic scenario & $(0.002)$ & $(0.192)$ \\
& $0.213^{* * *}$ & 0.212 \\
Distance to closest party & $(0.002)$ & $(0.191)$ \\
& $-1.361^{* * *}$ & -1.368 \\
Distance to closest party ${ }^{*}$ Policy scenario & $(0.012)$ & $(1.183)$ \\
& $0.95^{* * *}$ & 0.928 \\
Distance to closest party ${ }^{*}$ Deterministic scenario & $(0.013)$ & $(1.307)$ \\
& $1.302^{* * *}$ & 1.342 \\
Constant & $(0.013)$ & $(1.305)$ \\
$\mathrm{N}$ & $-1.232^{* * *}$ & $-1.228^{* * *}$ \\
Pseudo $\mathrm{R}^{2}$ & $(0.003)$ & $(0.313)$ \\
& $9,090,000$ & 1000 \\
\hline
\end{tabular}

Notes: ${ }^{*} \mathrm{p}<0.1,{ }^{* *} \mathrm{p}<0.05,{ }^{* *} \mathrm{p}<0.01$. 
from the party closest to her, the less likely it is that she will face incentives to vote strategically. This negative effect is moderated in scenarios with policy seeking coalition building rules and almost equalized in scenarios with deterministic rules. ${ }^{12}$ The negative sign could be surprising since one might expect voters with options close to their ideal points being in more favourable positions. This is still true with regard to the expected utilities over policy outcomes but appears to be different regarding the likelihood of strategic incentives.

The analysis of distances allows us to also discuss effects of different voter distributions. Our main dependent variable, the strategic share, counts every position in the policy space equally. This is adequate as we are interested in the share of positions with strategic incentives. Additionally, however, the share of voters having incentives to vote strategically is of interest and, as voters usually are not distributed equally over the policy space, these two shares are different. Assuming that parties, as rational actors, offer policy platforms at positions where voters agglomerate, it is reasonable to expect more voters at positions close to parties' positions than on positions farther away from the parties.

From this standpoint, a negative effect of the distance variable means that the share of voters with strategic incentives is even higher than the share of pure positions accompanied by strategic incentives, which would render the dilemma more important. While the effect of distance does not reach common levels of statistical significance when a realistic number of cases is observed and therefore our results for the share of positions should roughly also hold for the share of voters, the results depicted in Table 5 disclose another important finding: if anything, our previous analysis has underestimated the negative effect of parties' being motivated by policy concerns on the prominence of strategic incentives. According to Table 5, we would come up with higher strategic shares for the (non-deterministic) office scenarios if we assumed that voters are typically located relatively close to the parties. At the same time, under this assumption, we would arrive at almost the same or, in the case of deterministic policy scenarios, even lower strategic shares for the policy scenarios. Thus, assuming a uniform voter distribution leads to more conservative estimates.

\section{Conclusions}

In summary, our simulation study underscores the importance of taking variation with respect to the general rationale of coalition formation seriously. Both the manner of coalition building and party system characteristics affect the prevalence of strategic incentives in voting scenarios. As we argued in the introduction, incentives for strategic voting can be seen as problematic from a normative view. Firstly, they produce situations in which voters cannot vote both rationally with regard to policy outputs and expressively for their first preference but must make a choice between ratio and emotion. Secondly, at least some voters might not be able to detect the rational vote and thus do not vote for their own best

${ }^{12}$ This implies that the effect becomes positive for deterministic, policy-oriented scenarios. In bivariate scenario-wise regression, the sign is only positive in C6, while the distance variable is insignificant. 
even if they would like to do so.

In terms of implications, our simulation detects three key factors that should reduce this undesirable effect, two of them coming from coalition formation and one from party system characteristics. First, the higher the policy orientation of parties during coalition formation (and thus the smaller their office orientation), the fewer policy positions are concerned with the problem of strategic incentives. Parties, thus, can reduce the problem by predominantly signaling and building connected coalitions or at least coalitions with parties that are not too far away from their own policy position instead of focusing on office perks. Second, strict deterministic rules raise the strategic share. Therefore, parties can further minimize that issue by leaving the coalition formation process open and not excluding other parties generally as coalition partners. The more parties have a chance to be part of the government, the fewer voters have to vote strategically in order to influence policy for their own best. ${ }^{13}$ However, a more open stage of coalition formation could be considered undesirable on the grounds that it blurs the voter-government link by transferring the power of government-making from voters to parties. This clearly highlights that trade-offs emerge as we compare different (informal) institutional mechanisms of government formation. Third, incentives for strategic voting rise with party system fragmentation. While the stage of coalition bargaining typically only becomes unnecessary in plurality electoral systems, our results show that fragmentation continues to make a great difference among multi-party systems and therefore moderate party system fragmentation is preferable to highly fragmented party systems. As the latter are often associated with pure PR electoral systems, mixed electoral rules appear as a fruitful alternative. Said mixed electoral systems are also hoped to reach interparty efficiency via inducing the competition of two political blocs (see [42]). Applying the coalition building logic of bloc-competition our analysis has shown that it should also lead to a further decrease in strategic incentives while also distributing strategic incentives evenly across the policy space. Coalition formation according to strict office incentives or including policy considerations via the formation of minimal range coalitions should both lead to a more unequal distribution of strategic incentives across the policy space, the former placing the burden of higher strategic incentives on center positions, the latter on positions at the extremes of the policy space.

\section{References}

[1] Nohlen, D. (2009) Wahlrecht und Parteiensystem. Budrich, Opladen.

[2] Farrell, D.M. (2011) Electoral Systems: A Comparative Introduction. Palgrave Macmillan, New York. https://doi.org/10.1007/978-1-137-28550-8

[3] Reynolds, A., Reilly, B. and Ellis, A. (2005) Electoral System Design: The New In-

${ }^{13}$ Austria is a negative example here: before many elections, it was clear that the Social Democrats (SPÖ) and the People's Party (ÖVP) would form a Grand Coalition afterwards and that the only question is which of both parties would become the stronger and lead the government. This means that government policy could directly be influenced with a (for many voters strategic) vote for one of these two parties only. 
ternational IDEA Handbook. IDEA, Stockholm.

[4] Nohlen, D. (2009) Wahlsysteme in Reformprozessen. Zeitschrift für Politikwissenschaft, 19, 45-80. https://doi.org/10.5771/9783845219257-46

[5] Downs, A. (1957) An Economic Theory of Democracy. Harper \& Row, New York.

[6] Linhart, E. and Tepe, M. (2015) Rationales Wählen in Mehrparteiensystemen mit Koalitionsregierungen: Eine laborexperimentelle Untersuchung. Politische Vierteljahresschrift, 56, 44-76. https://doi.org/10.5771/0032-3470-2015-1-44

[7] Bargsted, M.A. and Kedar, O. (2009) Coalition-Targeted Duvergerian Voting: How Expectations Affect Voter Choice under Proportional Representation. American Journal of Political Science, 53, 307-323. https://doi.org/10.1111/j.1540-5907.2009.00372.x

[8] Indriðason, I.H. (2011) Proportional Representation, Majoritarian Legislatures, and Coalitional Voting. American Journal of Political Science, 55, 955-971. https://doi.org/10.1111/j.1540-5907.2011.00530.x

[9] Abramson, P.R., Aldrich, J.H., Blais, A., Diamond, M., Diskin, A., Indriðason, I.H., Lee, D.J. and Levine, R. (2009) Comparing Strategic Voting under FPTP and PR. Comparative Political Studies, 43, 61-90. https://doi.org/10.1177/0010414009341717

[10] Hobolt, S.B. and Karp, J.A. (2010) Voters and Coalition Governments. Electoral Studies, 29, 299-307. https://doi.org/10.1016/j.electstud.2010.03.010

[11] Cox, G.W. (1997) Making Votes Count: Strategic Coordination in the World's Electoral Systems. Cambridge University Press, Cambridge. https://doi.org/10.1017/CBO9781139174954

[12] Herrmann, M. (2015) Strategisches Wählen in Deutschland. Springer VS, Wiesbaden. https://doi.org/10.1007/978-3-658-09051-7

[13] Blais, A., Aldrich, J.H., Indriðason, I.H. and Levine, R. (2006) Do Voters Vote for Government Coalitions? Testing Downs' Pessimistic Conclusion. Party Politics, 12, 691-705. https://doi.org/10.1177/1354068806068594

[14] Kedar, O. (2005) When Moderate Voters Prefer Extreme Parties: Policy Balancing in Parliamentary Elections. American Political Science Review, 99, 185-199. https://doi.org/10.1017/S0003055405051592

[15] Meffert, M.F. and Gschwend, T. (2009) Voting for Coalitions? The Role of Coalition Preferences and Expectations in Voting Behavior. SFB 504 Working Paper No. 07-64, University of Mannheim, Mannheim.

[16] Armstrong, D.A. and Duch, R.M. (2010) Why Can Voters Anticipate Post-Election Coalition Formation Likelihoods? Electoral Studies, 29, 308-315. https://doi.org/10.1016/j.electstud.2010.03.007

[17] Herrmann, M. (2014) Polls, Coalitions and Strategic Voting under Proportional Representation. Journal of Theoretical Politics, 26, 442-467. https://doi.org/10.1177/0951629813505722

[18] Linhart, E. and Huber, S. (2009) Der Rationale Wähler in Mehrparteiensystemen: Theorie und experimentelle Befunde. In: Henning, C.H.C.A., Linhart, E. and Shikano, S., Eds., Parteienwettbewerb, Wahlverhalten und Koalitionsbildung, Nomos, Baden-Baden, 133-160. https://doi.org/10.5771/9783845216065-133

[19] Austen-Smith, D. and Banks, J. (1988) Elections, Coalitions, and Legislative Outcomes. American Political Science Review, 82, 405-422. https://doi.org/10.2307/1957393

[20] Schofield, N.J. and Sened, I. (2006) Multiparty Democracy: Elections and Legislative Politics. Cambridge University Press, Cambridge. 
https://doi.org/10.1017/CBO9780511617621

[21] Linhart, E. (2007) Rationales Wählen als Reaktion auf Koalitionssignale am Beispiel der Bundestagswahl 2005. Politische Vierteljahresschrift, 48, 461-484.

https://doi.org/10.1007/s11615-007-0087-5

[22] Linhart, E. (2009) A Rational Calculus of Voting Considering Coalition Signals: The German Bundestag Elections 2005 as an Example. World Political Science Review, 5, 1-28. https://doi.org/10.2202/1935-6226.1055

[23] Duch, R.M., May, J. and Armstrong, D.A. (2010) Coalition-Directed Voting in Multiparty Democracies. American Political Science Review, 104, 698-719. https://doi.org/10.1017/S0003055410000420

[24] Meffert, M.F. and Gschwend, T. (2011) Polls, Coalition Signals and Strategic Voting: An Experimental Investigation of Perceptions and Effects. European Journal of Political Research, 50, 636-667. https://doi.org/10.1111/j.1475-6765.2010.01986.x

[25] Meffert, M.F., Huber, S., Gschwend, T. and Pappi, F.U. (2011) More than Wishful Thinking: Causes and Consequences of Voters' Electoral Expectations about Parties and Coalitions. Electoral Studies, 30, 804-815. https://doi.org/10.1016/j.electstud.2011.08.001

[26] Riker, W.H. and Ordeshook, P.C. (1968) A Theory of the Calculus of Voting. American Political Science Review, 62, 25-42. https://doi.org/10.2307/1953324

[27] Buchanan, J.M. and Yoon, Y.J. (2006) All Voting Is Strategic. Public Choice, 129, 159-167. https://doi.org/10.1007/s11127-006-9021-4

[28] Poole, K.T. (2005) Spatial Models of Parliamentary Voting. Cambridge University Press, New York. https://doi.org/10.1017/CBO9780511614644

[29] McCarty, N.M. and Meirowitz, A. (2007) Political Game Theory: An Introduction. Cambridge University Press, Cambridge. https://doi.org/10.1017/CBO9780511813122

[30] Bandyopadhyay, S. and Oak, M.P. (2008) Coalition Governments in a Model of Parliamentary Democracy. European Journal of Political Economy, 24, 554-561. https://doi.org/10.1016/j.ejpoleco.2007.06.010

[31] Morgan, M.J. (1976) The Modelling of Governmental Coalition Formation: A Policy-Based Approach with Interval Measurement. PhD Dissertation, University of Michigan, Ann Arbor.

[32] Kollmann, K., Miller, J.H. and Page, S.E. (1997) Political Institutions and Sorting in a Tiebout Model. American Economic Review, 87, 977-992.

[33] Martin, C.W. and Plümper, T. (2005) Number of Parties, Endogenous Partisan Preferences and Electoral Turnout Rates: A Stochastic Equilibrium Analysis. Social Science Computer Review, 23, 347-359. https://doi.org/10.1177/0894439305275856

[34] Shikano, S. (2009) Simulating Party Competition and Vote Decision under Mixed Member Electoral Systems. AUCO Czech Economic Review, 3, 270-291.

[35] Golder, M., Golder, S.N. and Siegel, D.A. (2012) Modeling the Institutional Foundation of Parliamentary Government Formation. Journal of Politics, 74, 427-445. https://doi.org/10.1017/S0022381611001654

[36] Von Neumann, J. and Morgenstern, O. (1944) Theory of Games and Economic Behavior. Princeton University Press, Princeton.

[37] Gamson, W.A. (1962) Coalition Formation at Presidential Nominating Conventions. American Journal of Sociology, 68, 373-382. https://doi.org/10.1086/223306

[38] Riker, W.H. (1962) The Theory of Political Coalitions. Yale University Press, New 
Haven.

[39] Leiserson, M.A. (1968) Factions and Coalitions in One-Party Japan: An Interpretation Based on the Theory of Games. American Political Science Review, 62, 770-787. https://doi.org/10.2307/1953429

[40] Leiserson, M.A. (1966) Coalitions in Politics: A Theoretical and Empirical Study. PhD Dissertation, Yale University, New Haven.

[41] De Swaan, A. (1973) Coalition Theories and Cabinet Formations: A Study of Formal Theories of Coalition Formation Applied to Nine European Parliaments after 1918. Elsevier, Amsterdam.

[42] Shugart, M.S. (2001) Electoral "Efficiency" and the Move to Mixed-Member Systems. Electoral Studies, 20, 173-193. https://doi.org/10.1016/S0261-3794(00)00007-X

[43] Black, D. (1948) On the Rationale of Group Decision Making. Journal of Political Economy, 56, 23-34. https://doi.org/10.1086/256633

[44] Peleg, B. (1981) Coalition Formation in Simple Games with Dominant Players. International Journal of Game Theory, 10, 11-33. https://doi.org/10.1007/BF01770068

[45] Van Deemen, A.M.A. (1997) Coalition Formation and Social Choice. Kluwer, Dordrecht. https://doi.org/10.1007/978-1-4757-2578-0

[46] Axelrod, R. (1970) Conflict of Interest: A Theory of Divergent Goals with Application to Politics. Markham, Chicago.

[47] Davidovitch, L. and Ben-Haim, Y. (2010) Robust Satisficing Voting: Why Are Uncertain Voters Biased towards Sincerity? Public Choice, 145, 265-280. https://doi.org/10.1007/s11127-009-9565-1

[48] Laakso, M. and Taagepera, R. (1979) “Effective” Number of Parties: A Measure with Application to West Europe. Comparative Political Studies, 12, 3-27. https://doi.org/10.1177/001041407901200101

[49] Shikano, S. (2006) Bootstrap und jackknife. In: Behnke, J., Gschwend, T., Schindler, D. and Schnapp, K.-U., Eds., Methoden der Politikwissenschaft, Nomos, Baden-Baden, 69-79.

[50] Gschwend, T. and Hooghe, M. (2008) Should I Stay or Should I Go? An Experimental Study on Voter Responses to Pre-Electoral Coalitions. European Journal of Political Research, 47, 556-577. https://doi.org/10.1111/j.1475-6765.2008.00787.x

[51] Dalton, R.J. (2008) The Quantity and the Quality of Party Systems: Party System Polarization, Its Measurement, and Its Consequences. Comparative Political Studies, 41, 899-920. https://doi.org/10.1177/0010414008315860

[52] Laver, M. and Benoit, K. (2015) The Basic Arithmetic of Legislative Decisions. American Journal of Political Science, 59, 275-291.

https://doi.org/10.1111/ajps.12111 


\section{Appendix I}

For the reasons we outlined introducing our model, we estimate ego's expected utility values $E u_{\text {ego }}\left(A_{k}\right)$ with help of approximations $\widehat{E u}_{\text {ego }}\left(A_{k}\right)$. Results for $E u$ and $\widehat{E u}$ are almost identical; errors do not occur systematically. This approximation works as follows. We first identify the seat distribution according to the simulated poll by applying the Sainte-Laguë PR method. We assume the uncertainty of the poll being exactly so large that a party could win or lose not more than one seat. For the majority of the states of the worlds, ego's vote does not change the seat distribution at all, independent of which party she is voting for. Since the respective utility values are constant over all alternatives, they can be excluded from the subsequent computation. Further, as we use a strict PR rule, the numbers of states of the world in which ego is pivotal when voting for a party $P_{k}$ are roughly of equal size for all parties. This means that we do not have to care about how often ego is pivotal because this number is equal for all parties. If then, one of the parties $P_{k}$ gains one additional seat, one of the other parties loses one. For the same reason as discussed above, we consider all other parties as equally probable to be this seat loser. Given a seat distribution $S=\left(s_{1}, s_{2}, \cdots, s_{k}, \cdots, s_{n}\right)$, we therefore compute

$$
\begin{aligned}
\widehat{E u}_{\text {ego }}\left(A_{k}\right)= & {\left[\left(s_{1}-1, s_{2}, \cdots, s_{k}+1, \cdots, s_{n}\right)+\left(s_{1}, s_{2}-1, \cdots, s_{k}+1, \cdots, s_{n}\right) .\right.} \\
& \left.+\cdots+\left(s_{1}, s_{2}, \cdots, s_{k}+1, \cdots, s_{n}-1\right)\right] /(n-1)
\end{aligned}
$$

$E u_{\text {ego }}\left(A_{k}\right)$ and $\widehat{E u}_{\text {ego }}\left(A_{k}\right)$, certainly, take very different values because of different (or lacking, respectively) normalizations. The alternatives $A_{k}$, however, which solve the maximization problems are the same aside from very rare cases.

\section{Appendix II: Summary Statistics of the Simulated} Party Systems

\begin{tabular}{ccccccc}
\hline $\begin{array}{c}\text { Number of } \\
\text { parties } N\end{array}$ & $\begin{array}{c}\text { Fragmentation } \\
\text { (stand. dev.) }\end{array}$ & $\begin{array}{c}\text { Polarization } \\
\text { (stand. dev.) }\end{array}$ & Top-three & $\begin{array}{c}\text { Strongly } \\
\text { dominant } \\
\text { party }\end{array}$ & Top-two & Open \\
\hline 3 & $2.763(0.189)$ & $0.265(0.117)$ & $100 \%$ & $0 \%$ & $0 \%$ & $0 \%$ \\
4 & $3.339(0.374)$ & $0.276(0.092)$ & $60.5 \%$ & $39.6 \%$ & $0 \%$ & $0 \%$ \\
5 & $3.984(0.511)$ & $0.281(0.077)$ & $25.4 \%$ & $47.3 \%$ & $17.9 \%$ & $9.5 \%$ \\
6 & $4.706(0.608)$ & $0.282(0.066)$ & $6.6 \%$ & $24.5 \%$ & $30.9 \%$ & $38.1 \%$ \\
7 & $5.450(0.670)$ & $0.283(0.060)$ & $1.9 \%$ & $8.1 \%$ & $19.2 \%$ & $70.8 \%$ \\
$3-7$ & $4.048(1.078)$ & $0.278(0.086)$ & $38.9 \%$ & $23.9 \%$ & $13.6 \%$ & $23.7 \%$ \\
\hline
\end{tabular}

For each number of parties, the table shows the average fragmentation, the average polarization, ${ }^{14}$ the respective standard deviations and the distribution to types of party systems. For the latter, we use Laver and Benoit's categorization system [52]. It is not surprising that party system fragmentation increases with the number of parties. At the same time the effective number of parties is, on ${ }^{14}$ As index for fragmentation we use Laakso and Taagepera's effective number of parties [48]. For the measurement of polarization, see footnote 10 in the main text. 
average, lower than the pure number of parties for each $N$, reflecting unequal size distributions - which is of course reflective of the situation in real cases. On the other hand, we see that party system polarization is almost independent of the number of parties while there is sufficient variation within each group. This feature of the simulated data will make it easier for us to cleanly estimate the effects of fragmentation and polarization.

We further see that the more parties we include, the fewer party systems fall into the rather concentrated categories top-three (with at least three two-party winning coalitions) and "strongly dominant party" (with at least two two-party winning coalitions) and the more correspond to more fragmented top-two (with one two-party winning coalition only) or "open" party systems (without any two-party winning coalition). Reassuringly, these patterns of our simulated data match those identified for actual data from European legislative elections by Laver and Benoit, although there is a greater tendency for the simulated party systems to be of the open type as the number of parties increases-likely caused by the random assignment of party sizes from a uniform distribution [52]. However, our simulated data seems to be sufficiently similar to actual data in order to generalize our results.

\section{Appendix III: Summary Statistics for the Shares of Strategic Votes by Scenario}

\begin{tabular}{ccc}
\hline Scenario & Mean (standard deviation) & Minimum; maximum \\
\hline C1 & $0.672(0.013)$ & $0.648 ; 0.692$ \\
C2 & $0.648(0.020)$ & $0.603 ; 0.675$ \\
C3 & $0.713(0.013)$ & $0.691 ; 0.739$ \\
C4 & $0.477(0.057)$ & $0.381 ; 0.549$ \\
C5 & $0.605(0.033)$ & $0.552 ; 0.642$ \\
C6 & $0.613(0.047)$ & $0.536 ; 0.670$ \\
C7 & $0.576(0.080)$ & $0.454 ; 0.678$ \\
C8 & $0.567(0.291)$ & $0 ; 1$ \\
C9 & $0.542(0.024)$ & $0.476 ; 0.563$ \\
\hline
\end{tabular}

Notes: The extreme minimum and maximum values for C8 stem from the fact that this scenario always sees a bloc of parties consisting of the median party and all parties left of it forming the government. While this formation rule can be used without loss of generality for all other analyses in this paper this does not hold for the summary statistics reported here. An adapted rule randomly choosing the left or right bloc deterministically would lead to statistics similar to those of C9. 